$\frac{18}{8} 2 \sqrt{2}+45950$

UCRL-ID-119602

\title{
Progress Toward Uranium Scrap Recycling via Electron Beam Cold Hearth Refining
}

\author{
R. H. McKoon
}

December 15, 1994

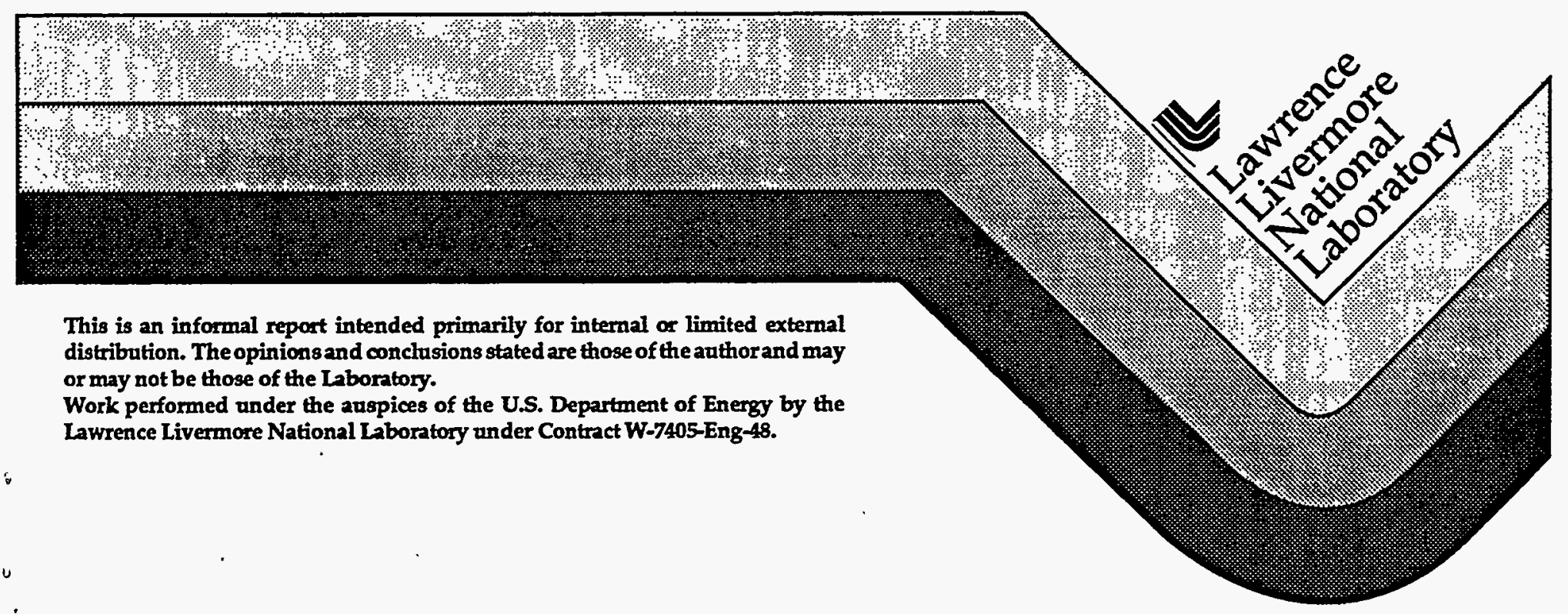




\section{DISCLAIMER}

This document was prepared as an account of work sponsored by an agency of the United States Government. Neither the United States Government nor the University of California nor any of their employees, makes any warranty, express or implied, or assumes any legal liability or responsibility for the accuracy, completeness, or usefuiness of any information, apparatus, product, or process disclosed, or represents that its use would not infringe privately owned rights. Reference herein to any specific commercial product, process, or service by trade name, trademark, manufacturer, or otherwise, does not necessarily constitute or imply its endorsement, recommendation, or favoring by the United States Government or the University of California. The views and opinions of authors expressed herein do not necessarily state or reflect those of the United States Government or the University of Califomia, and shall not be used for advertising or product endorsement purposes.

This report has been reproduced directly from the best available copy.

Available to DOE and DOE contractors from the Office of Scientific and Technical Information

P.O. Box 62, Oak Ridge, TN 37831

Prices available from (615) 576-8401, FTS 626-8401

Available to the public from the National Technical Information Service

U.S. Department of Commerce 5285 Port Royal Rd. Springfield, VA 22161 


\section{DISCLAIMER}

Portions of this document may be illegible in electronic image products. Images are produced from the best available original document. 


\title{
PROGRESS TOWARD URANIUM SCRAP RECYCLING VIA ELECTRON BEAM COLD HEARTH REFINING
}

\author{
Robert H. McKoon \\ Lawrence Livermore National Laboratory \\ Livermore, CA
}

December 15, 1994
Prepared for the Strategic Environmental Research and Development Program in support of 1993 SERDP DOE project on Electron Beam
Melting and In-Process Scrap Recycling of Uranium




\begin{abstract}
A $250 \mathrm{~kW}$ electron beam cold hearth refining (EBCHR) melt furnace at Lawrence Livermore National Laboratory (LLNL) has been in operation for over a year producing 5.5 in.-diameter ingots of various uranium alloys. Production of in-specification uranium$6 \%$ - niobium $(\mathrm{U}-\mathrm{G} \mathrm{Nb}$ ) alloy ingots has been demonstrated using virgin feedstock. A vibratory scrap feeder has been installed on the system and the ability to recycle chopped $\mathrm{U}-6 \mathrm{Nb}$ scrap has been established. A preliminary comparison of vacuum arc remelted (VAR) and electron beam (EB) melted product is presented.
\end{abstract}

\title{
Introduction
}

Due to a rather unique set of properties, uranium and its alloys have been found useful in a variety of applications, from nuclear-weapons components to counterweights in commercial aircraft. One such alloy of uranium and $6 \mathrm{wt} . \%$ niobium has been used for decades in applications requiring a relatively high corrosion resistance, which pure uranium does not possess ${ }^{1,2}$. In the U.S., this U- $6 \mathrm{Nb}$ alloy has historically been manufactured at two Department of Energy (DOE) sites in Rocky Flats, CO, and Oak Ridge, TN.

In the production of $U-6 \mathrm{Nb}$ alloy parts at the $\mathrm{Y}-12$ manufacturing complex at Oak Ridge, $\mathrm{TN}$, the majority of the uranium used ends up as non-recyclable scrap or as process waste. Approximately half of this waste is a direct result of alloy production and the remaining half results from thermo-mechanical component fabrication processes. This low production yield is a result of the current multi-step melting procedure shown in Figure 1, which, in addition to being rather inefficient, creates substantial environmental, safety and health liabilities and results in high production costs.

By utilizing a single step EBCHR process, approximately $80 \%$ of the uranium scrap and waste generated under current manufacturing methods can be eliminated. It is estimated that in addition to the obvious gains in processing efficiency, this process change will also reduce radiation-exposure levels to plant workers by about $30 \%$ due to the decrease in the amount of handling required. Further, the ability to recycle what is now scrap can reduce the requirement for virgin feedstock to zero for the foreseeable future by simply working down current inventories of stored scrap material.

In 1993, LLNL retrofitted an existing, on-site, uranium-qualified vacuum processing system to an EBCHR furnace. The objective was to develop a single-step, electron beam cold hearth melting and casting process to produce the U- $\mathrm{Nb}$ alloy, which would meet current composition and homogeneity specifications while generating little waste and, hopefully, to produce a purer product, lower in tramp impurities than the conventional 3-step VAR material.

The furnace retrofit was completed on time and within budget. In 1994, funding was obtained to demonstrate the capability of producing 5.5 in.-diameter $\mathrm{U}-6 \mathrm{Nb}$ ingots 
The furnace retrofit was completed on time and within budget. In 1994, funding was obtained to demonstrate the capability of producing 5.5 in.-diameter U- $6 \mathrm{Nb}$ ingots meeting Y-12 specifications and to design and construct a scrap feeder capable of recycling chopped Y-12 plate scrap. A modeling effort was also initiated to better understand the relationships between input process parameters and final ingot structure.

\section{Recycling Bulk Scrap}

The normal practice of recycling pure uranium metal bulk scrap via vacuum induction melting (VIM) is somewhat of a problem for the uranium-niobium system. Uranium and its alloys are normally vacuum induction melted in graphite crucibles. As uranium is highly refractory and reacts readily with carbon above the melting temperature of uranium $\left(1132^{\circ} \mathrm{C}\right.$ ), crucibles are normally coated with a refractory metal oxide (usually $\mathrm{ZrO}_{2}$ or $\mathrm{Y}_{2} \mathrm{O}_{3}$ ) to prevent excessive carbon pickup in the final product. Figure 2 shows the nominal operating temperature regimes for various crucible coating materials and the expected carbon pickup during melting as a function of melting temperature.

Figure 3 shows the binary phase diagram for the uranium-niobium system ${ }^{3}$. Note that the liquidus for a $6 \%(\mathrm{wt})$ alloy is around $1350^{\circ} \mathrm{C}$. Normal VIM practice for this material is to operate the liquid metal bath at around $1500^{\circ} \mathrm{C}$ to insure complete dissolution of niobium. At this temperature, even yttria and zirconia coatings offer only limited protection for the liquid metal and result in a product high, and frequently out of specification, in carbon. This has forced the Y-12 plant into the complicated, 3-step VIM/VAR melt procedure shown in Figure 1, and limits the type and percentage of scrap that may be reverted.

Much of the scrap generated in the manufacture of U- $\mathrm{Nb}$ parts is in the form of .25-.50 in.- thick plate left over from shearing and machining operations. Using conventional melt practice, only about $50 \%$ of this material is reverted. The balance, many tons, currently accumulates in barrels at the Y-12 Plant. This scrap material was identified as a prime candidate for recycling via EBCHR and LLNL took this task on as a goal for 1994. It was found that this material could be readily cleaned, chopped into 3 in. pieces at Y-12 and shipped to Livermore for about $\$ 3 / \mathrm{lb}$. As-cast ingots of $U-6 \mathrm{Nb}$ produced from this scrap have a value of about $\$ 30 / \mathrm{lb}$. So, besides the environmental, safety, and health issues associated with storing large quantities of scrap uranium, there appeared to be a strong economic driver for the development of a one-step melting process to revert uranium scrap.

The LLNL melt furnace was originally designed to feed uranium and niobium to a cooled copper hearth in the form of 2 in.-diameter rods and to cast ingots $5.5 \mathrm{in}$. diameter by 24 in. long. To accommodate chopped plate scrap, a vibratory feed approach was selected. As the existing furnace design and location precluded installation of a vacuum lock and ingot can, and as the casting configuration limited ingot production to a maximum of $170 \mathrm{~kg}$, it was decided to make the vibratory feed system a batch process and to mount the vibratory feeder assembly inside the vacuum chamber. The required hopper volume for the measured bulk density of 3 in. chopped scrap was found to be less than 
$1 \mathrm{ft}^{3}$. The hopper was purposely oversized, however, at $1.5 \mathrm{ft}^{3}$ to allow for possible future furnace modification to accommodate the production of larger ingots. A commercially available system was purchased from B.E.S.T., Inc., of Cleveland, $\mathrm{OH}$, and retrofitted onto the existing furnace. The completed assembly is shown in Figure 4 and the system as-installed is shown in figure 5 . The new feeder was started up uneventfully and the first ingot was cast from $100 \%$ scrap in late July.

\section{Ingot Characterization}

There is much information in the available literature on $\mathrm{U}-\mathrm{Nb}$ produced by the conventional 3-step $Y-12$ process. To date, however, limited data has been generated to characterize the single step EBCHR material produced from both virgin and scrap feed stock and to compare it with typical VAR material. It should be recognized, therefore, that the results reported here are preliminary in nature and will be updated as a more statistically significant number of samples are generated.

The U-6Nb alloy is made to a Y-12 chemistry specification shown in Table 1. The sampling procedure calls for analysis of samples from the top center and edge, and the bottom center of each ingot. In this study, niobium was analyzed by inductively coupled plasma optical emission spectroscopy. Carbon was analyzed via a standard LEECO carbon analyzer, and tramp impurities in the low ppm range were analyzed via DC arc emission spectroscopy.

For this initial comparison, 3 ingots were produced from virgin feedstock at constant conditions of melt rate, power input, and beam deflection pattern. Two inches were cropped from the top and bottom of each ingot and analytical samples were generated from the edges and centers of both ends of the remaining central ingot portions. The ingots were then cut longitudinally and additional samples taken along the length at center and edge. Finally, a thin, longitudinal slice was generated for metallographic analysis. 
Table 1. U-6Nb Chemical Specification.

\begin{tabular}{|l|l|l|}
\hline & Min. by wt. & $\begin{array}{l}\text { Max. by } \\
\text { wt. }\end{array}$ \\
\hline Uranium & $93.0 \%$ & --- \\
\hline Niobium & $5.2 \%$ & $6.5 \%$ \\
\hline Zirconium & --- & 500 ppm \\
\hline Carbon & --- & 200 \\
\hline Iron & --- & 150 \\
\hline Silicon & --- & 150 \\
\hline Copper & --- & 100 \\
\hline Nickel & --- & 75 \\
\hline Aluminum & --- & 75 \\
\hline Molybdenum & --- & 75 \\
\hline Titanium & --- & 75 \\
\hline
\end{tabular}

\section{Chemistry}

Preliminary analytical results from the three ingots produced from virgin feedstock are given in Table 2. A wide variation is seen in niobium content, with numbers ranging from near the lower specification limit to slightly above the upper specification limit. This alloy is known to segregate badly however, and the results are consistent with previously reported values ${ }^{4}$. Tramp impurity levels are very low, which is also consistent with previously reported results for electron beam melted uranium ${ }^{5}$.

Carbon levels should theoretically remain stable during EBCHR of U- $\mathrm{Nb}$. There is no mechanism by which carbon should be added during the melting and refining process. In fact, one of the major advantages of cold hearth melting is that the process does not contaminate material being melted with a reactive containment vessel. Neither, however, should carbon be reduced. Thermodynamic free energy calculations do not favor carbon loss via reaction with entrained oxides in the liquid phase or through flotation or volatilization of free carbon. As an experiment in verifying the stability of carbon, one ingot -M061594- was cast from known high-carbon feedstock under controlled process conditions. Subsequent analysis of samples taken along the length of the ingot indicated that carbon did indeed remain stable during the EBCHR process. If a mechanism could be identified for carbon removal during the melting process, many tons of what is currently high-carbon scrap could be recovered. 
Table 2 - Ingot Analysis.

\begin{tabular}{|l|l|l|l|}
\hline Ingot Number & M060794 & M061094 & M061594 \\
\hline Feedstock & Virgin U+Nb & Virgin U+Nb & Virgin U+Nb \\
\hline Melt rate - kg/hr & 70 & 86 & 46 \\
\hline Cast rate - in/hr & 10.7 & 13.9 & 7.4 \\
\hline Starting C - ppm & 85 & 85 & 380 \\
\hline Final C - ppm & - & - & 360 \\
\hline Starting Nb - wt. \% & 6.0 & 6.0 & 6.0 \\
\hline Bottom Nb - edge/center & $5.51 / 5.40$ & $6.06 / 2.95^{*}$ & $6.25 / 5.79$ \\
\hline Top Nb - edge/center & $6.55 / 5.41$ & $6.80 / 6.38$ & $6.46 / 6.20$ \\
\hline Zirconium - ppm & $<10$ & $<10$ & $<10$ \\
\hline Iron & $<14$ & $<14$ & $<14$ \\
\hline Silicon & 8 & 7 & 9 \\
\hline Copper & 3 & 3 & 3 \\
\hline Nickel & $<4$ & $<4$ & $<4$ \\
\hline Aluminum & $<15$ & $<15$ & $<15$ \\
\hline Molybdenum & $<2$ & $<2$ & $<2$ \\
\hline Titanium & $<8$ & $<8$ & $<8$ \\
\hline
\end{tabular}

* Low $\mathrm{Nb}$ reflects out of spec starter stub

$<$ Denotes lower limit of detectability

\section{Metallography}

The .25 in. thick longitudinal sections from both the VAR and EBCHR ingots were polished and air oxidized to bring out detail. Figure 6 shows the as-cast macrostructure of longitudinal ingot sections of the VAR and EBCHR ingots. The VAR material is 8.3 in. diameter, and was melted using approximately $900 \mathrm{amps}$ of arc current at a linear casting rate of $56 \mathrm{in} / \mathrm{hr}$. The EBCHR material is $5.5 \mathrm{in}$. diameter, and cast with $35 \mathrm{~kW}$ of EB power programmed on the ingot as an annular ring approximately 4 in. diameter and 1 in. wide, and at a linear casting rate of $7 \mathrm{in.} / \mathrm{hr}$.

The U- $6 \mathrm{Nb}$ alloy is known to segregate badly on solidification ${ }^{4}$ and this is seen in Figure 6 as light and dark banding, the light areas being niobium rich. Because of the differences in casting rates and ingot diameters, it is difficult to draw firm.conclusions from this data. Producing the flatter solidification plane seen in the EBCHR ingot by judicious programming of the electron beam on the ingot is, however, one of the objectives of the program. It is expected that this flat solidification plane will result in better compositional uniformity along the length and cross section of the ingot. It will be interesting to see just how flat this plane can be maintained at higher casting rates.

A preliminary comparison was made of the microstructures of the EB and VAR materials. Transverse slices .25 in. thick were taken from the 8 in. VAR and the 5.5 in. EB melted 
ingots. Metallographic samples were then generated from the edge, mid-radius, and center of each ingot slice and mounted and polished using standard metallographic techniques. The microstructures of the VAR and EB products shown in Figure 7 are markedly different. The VAR microstructure appears similar to other published studies ${ }^{6}$, with well defined grain boundaries and faceted carbides in evidence. The EB product shows evidence of eutectoid decomposition to alpha uranium and a metastable gamma phase. This is undoubtedly a result of different cooling rates between the two samples and is not considered significant. At higher magnification, both samples show expected levels of carbides consistent with known input material compositions.

\section{Future Work}

The viability of the single-step EBCHR process to produce U- $6 \mathrm{Nb}$ alloy from both virgin and scrap material has been demonstrated. The goals over the next few years are to continue process development and comparison of the EBCHR product with the baseline arc melted material. Complete recycle capability for uranium and uranium alloys will be provided by demonstrating the ability to recycle scrap machine chips via EBCHR. A further goal is to modify the existing melt furnace to allow for the production of up to 8 in. diameter uranium ingots to provide compatibility with current fabrication practice.

The existing EBCHR furnace at LLNL currently has sufficient capacity to meet projected $D O E$ needs for the U- $6 \mathrm{Nb}$ alloy for the forseeable future and could, in fact, become a production facility should the need arise. If a new installation is deemed necessary, suffieient engineering information has been generated from this current SERDP funded project to optimally specify hearth size, electron beam gun design and power and feeding systems for both virgin and recycled bulk scrap materials. The design of a facility capable of low-grade machine chip recycling will require further development. As always, the level of funding for the project will determine the actual schedule. 


\section{$\underline{\text { References }}$}

(1) W.D. Wilkinson: "Uranium Metallurgy," Interscience Publishers, New York, NY, 1962, vol. 2.

(2) J.H. Gittus: "Uranium," Butterworths, London, 1963.

(3) R.P. Elliott: "Constitution of Binary Alloys, First Supplement," McGraw-Hill Book Company, San Francisco, CA, 1965.

(4) W.G. Northcutt, Jr.: "Use of $\mathrm{x}$-ray Fluorescence to Study Vacuum Arc Remelting of a Uranium-6 Niobium Alloy," Proceedings of the October 1983 JOWOG 22 Uranium Alloy Meeting, Albuquerque, NM, pg. 45.

(5) H. Eikenberry: "Electron Beam Melting Of Uranium," AEC Research and Development Report, NLCO-881, June 14, 1963.

(6) K.H. Eckelmeyer, A.D. Romig, Jr., and L.J. Weirick: "The Effect of Quench Rate on the Microstructure, Mechanical Properties, and Corrosion Behavior of U-6Wt Pct Nb," Metallurgical Transactions A, vol. 15A, July 1984, pg. 1319. 


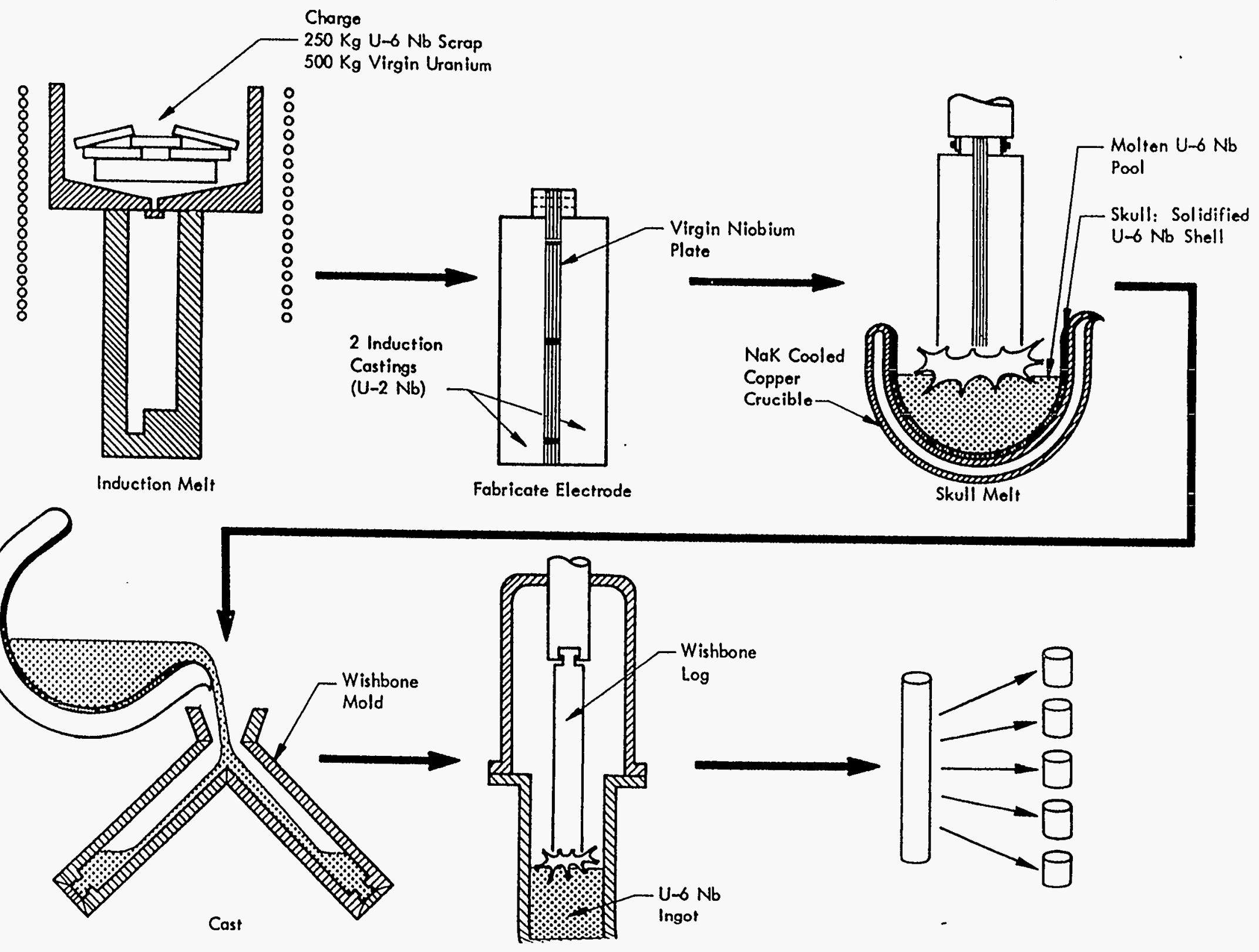

Figure 1: Current VIM/VAR production route for $\mathrm{U}-6 \mathrm{Nb}$ alloy. 


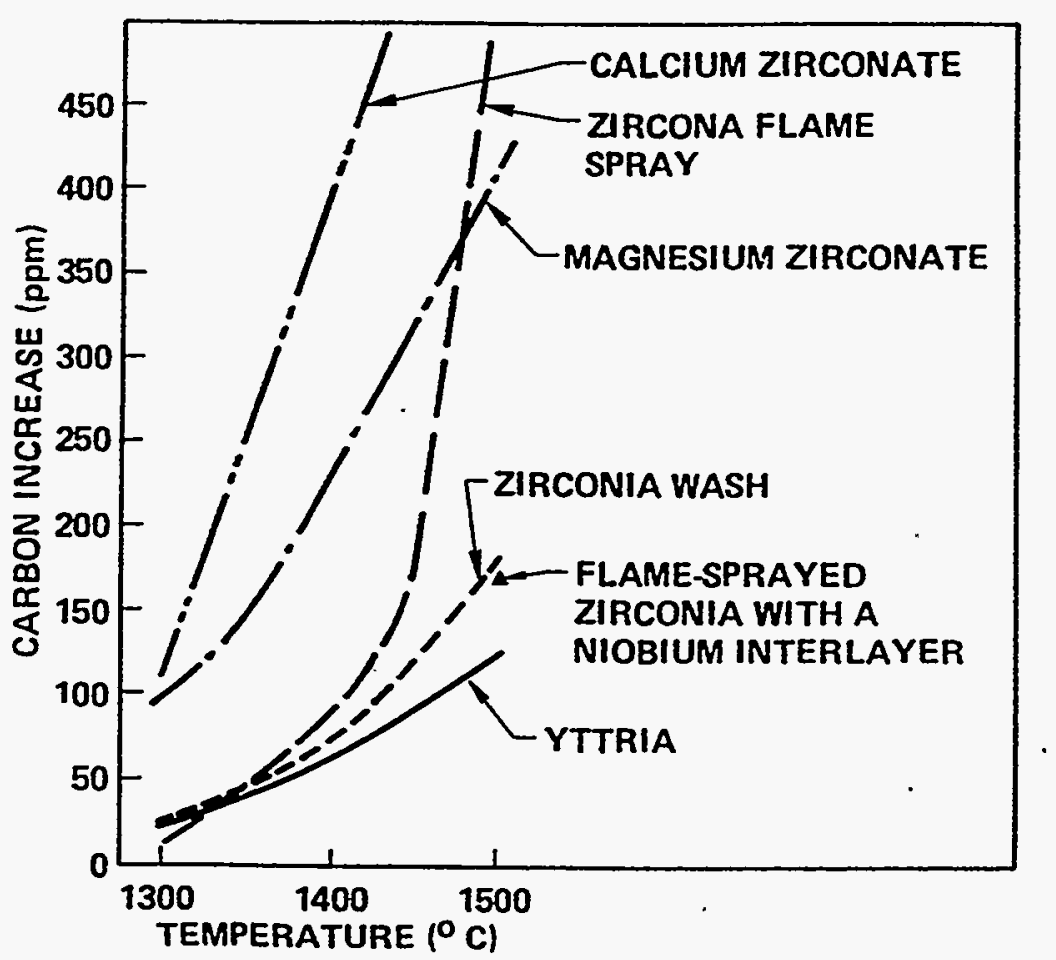

Figure 2: Average carbon increase as a function of temperature and crucible coating material.

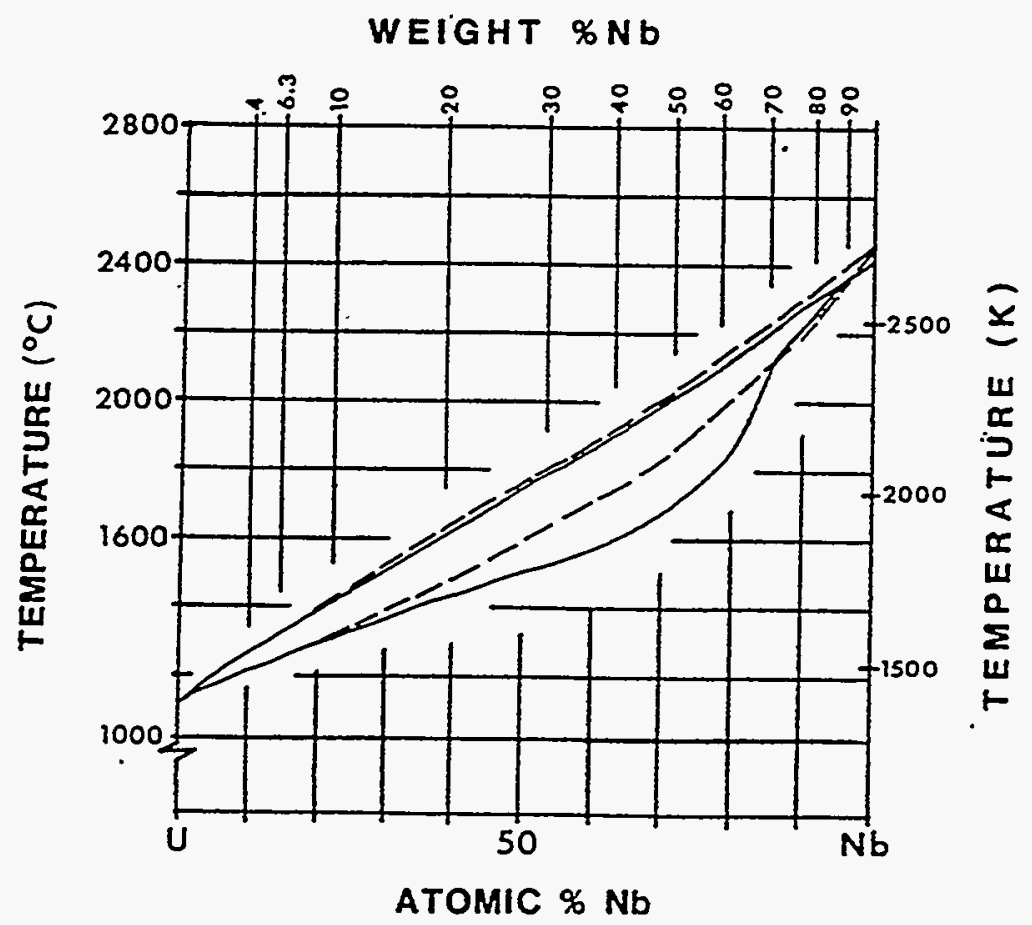

Figure 3: U-Nb binary phase diagram. 


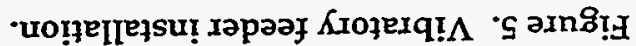

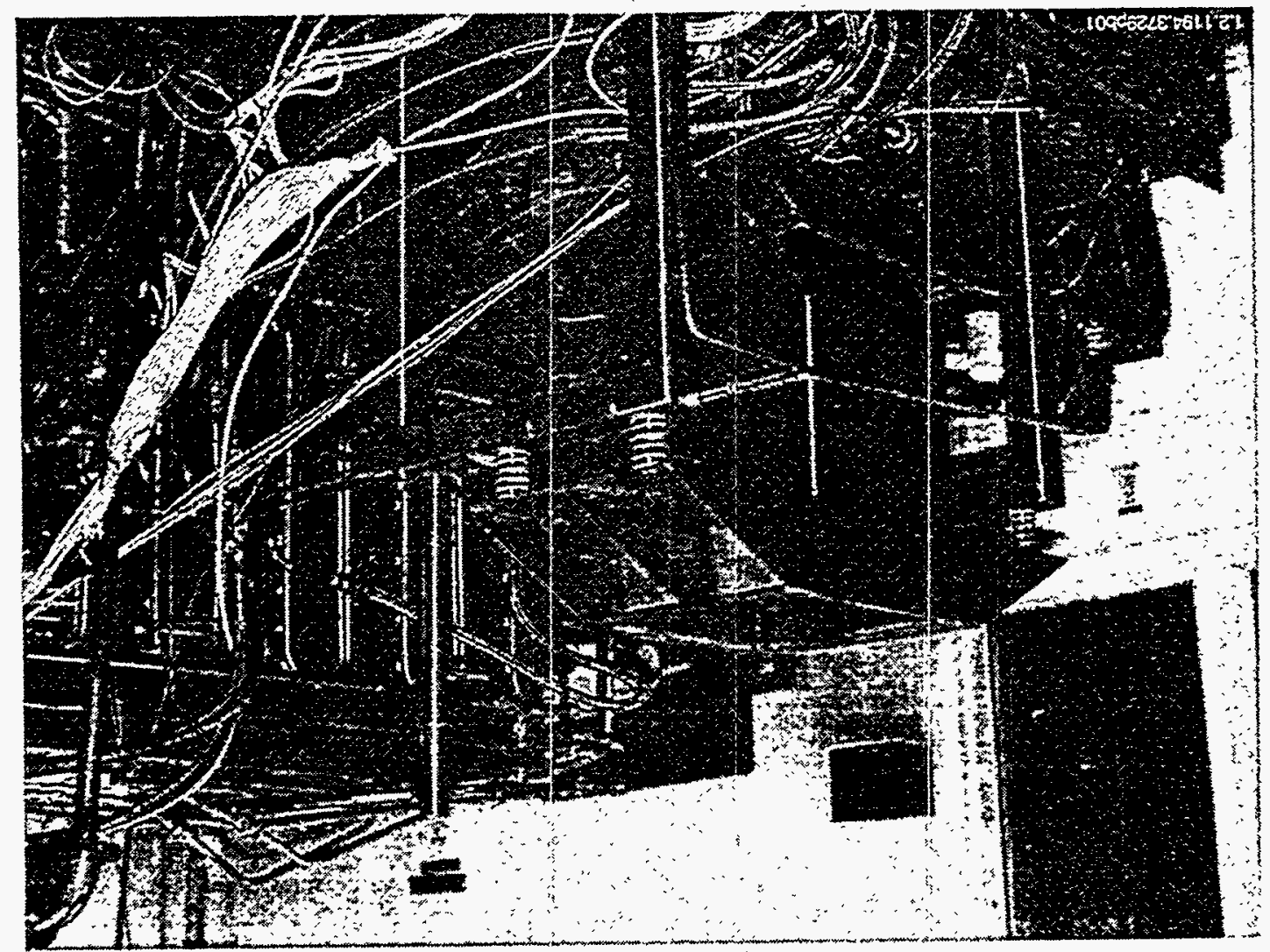

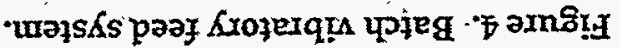

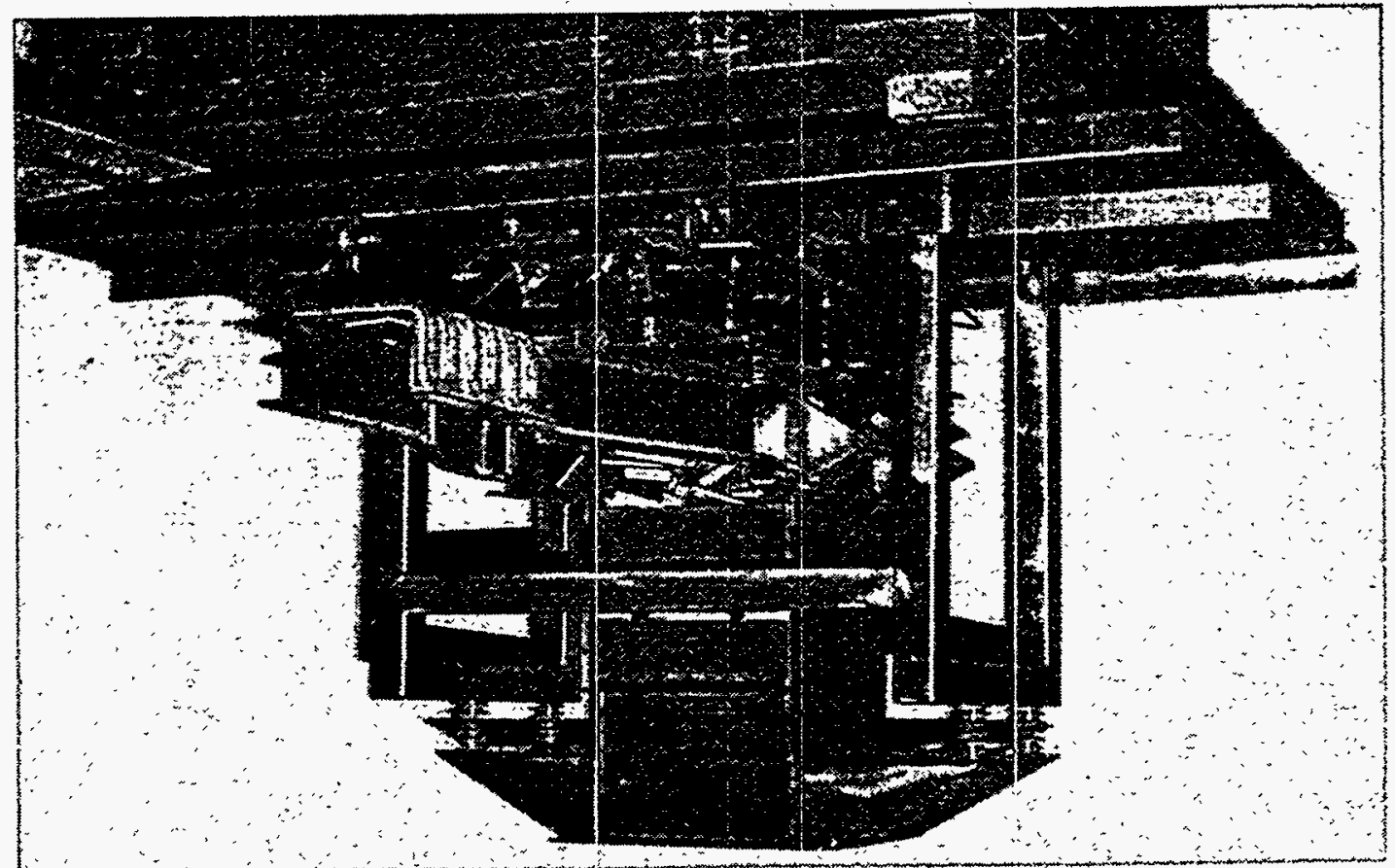




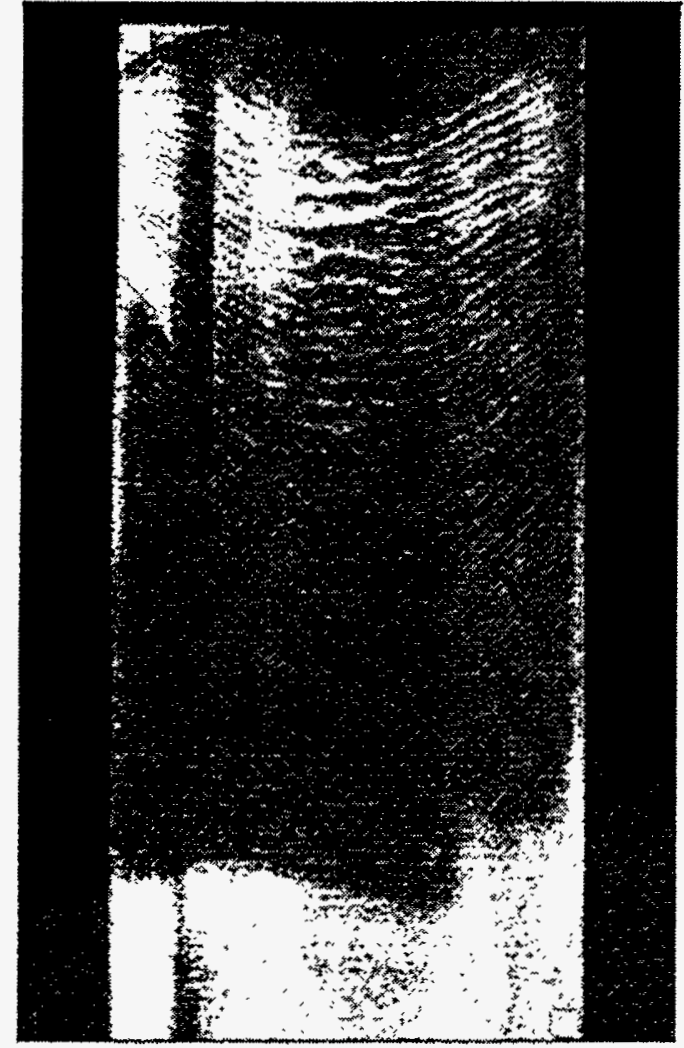

(a)

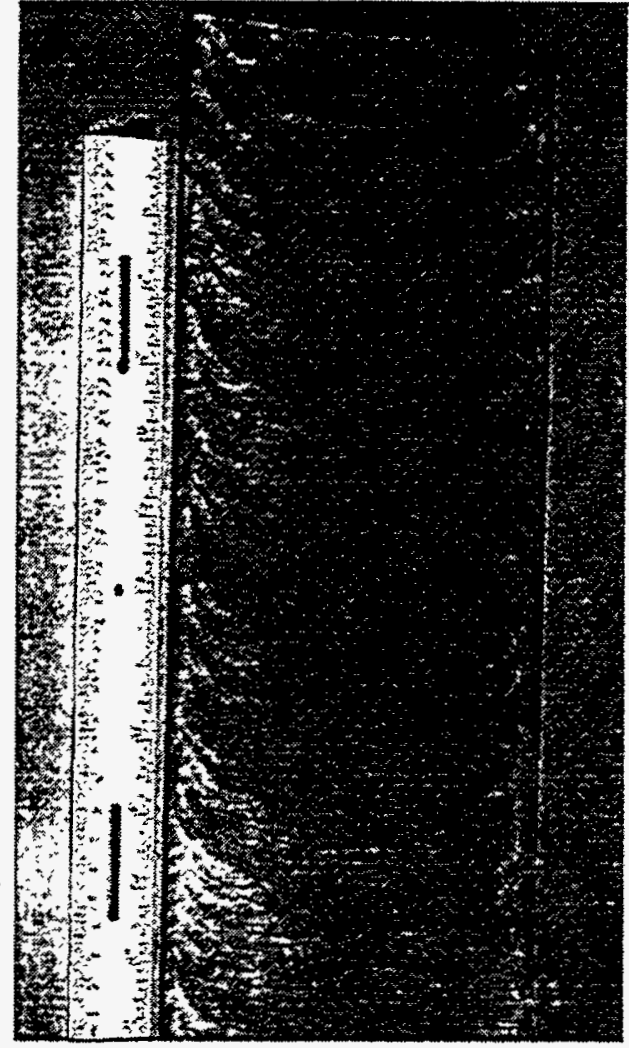

(b)

Figure 6: As-cast VAR (a) and EB (b) longitudinal sections.

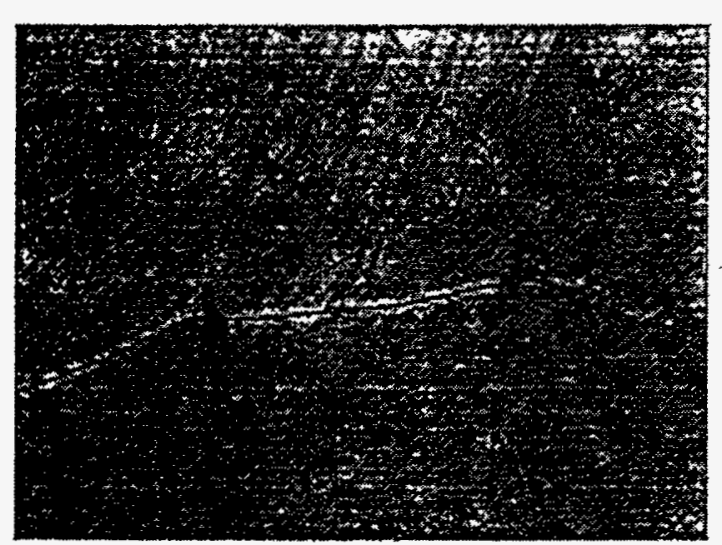

(a)

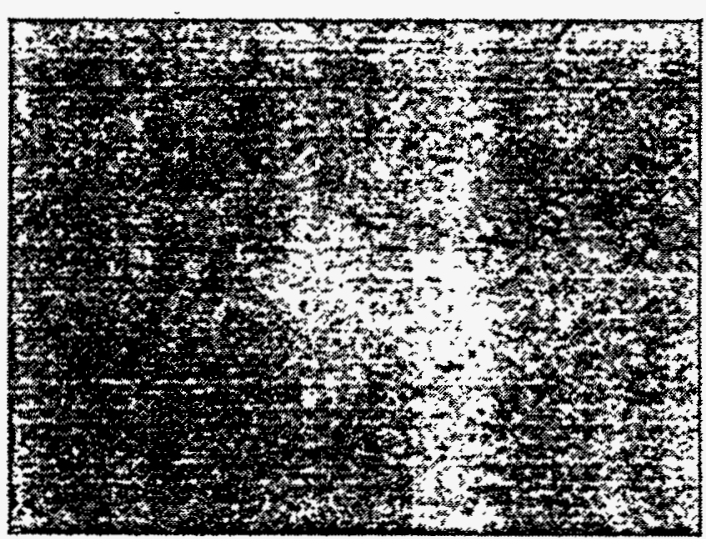

(b)

Figure 7: As-cast VAR (a) and EB (b) microstructures-100x.

1.2.1094.3604pb01 